\title{
Physical and Mechanical Properties of Industrial Waste Modified Mortar
}

Norsuzailina Mohamed Sutan ${ }^{1, a}$, Ibrahim Yakub ${ }^{1, b}$ and Hebron Jau ${ }^{1, c}$

${ }^{(1)}$ Faculty of Engineering, Universiti Malaysia Sarawak,94300 Kota Samarahan, Sarawak, Malaysia

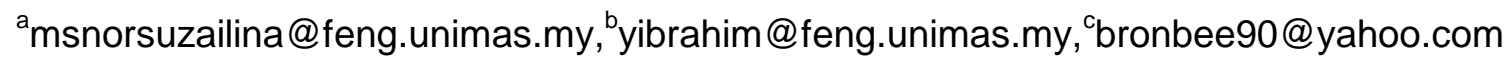

Keywords: Compressive Strength, Porosity, Micro Silica, Finely Ground Waste Vase

Abstract. This paper presents and discusses the results of the study on physical and mechanical properties of Industrial Waste Modified Mortar (IWMM) in comparison to Unmodified Mortar (UM). Industrial wastes used as ternary cement replacement were Micro Silica (MS) and Finely Ground Waste Vase (FGWV). Porosity and compressive strength of cement based products are the crucial properties that reflect the durability. Results of this study showed incorporation of $15 \% \mathrm{MS}$ and $20 \%$ FGWV as ternary binders reduced $32.8 \%$ porosity and increased $4.3 \%$ compressive strength of mortar.

\section{Introduction}

In recent decade sustainability and durability as key issues are greatly raised in the construction industry where one of the main concerns is the more efficient use of waste materials as cement replacements to reduce the energy demand of recycling and waste management [1]. Previous studies found alternative materials that can be used as cement replacement, otherwise without proper waste management and recycling practice, these wastes impose a threat to the environment. The main industrial waste materials include Micro Silica, Rice Husk Ash, Fly Ash, Waste Glass, Waste Vase and etc.

Studies have shown that durability properties of cement based products can be improved by incorporating these materials as partial cement replacements through microstructural improvement specifically through pozzolanic reactions that can improve their strength and porosity $[2,3,4,5,6]$. These materials possessed pozzolanic properties from their high silica content and large surface area. Pozzolanic material can significantly increase the strength and reduce the permeability of mortar as early as after 24 hours hydration process has taken place [2,3,4,5,6,7].

Besides the previously mentioned pozzolanic wastes, industrial waste from pottery industry in Kuching, Sarawak such as defect vases, faces the same waste management problem. Defect during the production usually take up $1 \%$ from the whole production. Hypothetically, Kaolin clay vase can manifest pozzolanic properties if it is finely ground to increase its surface area $[8,9,10,11]$. Therefore it is the motivation of this study to assess the potential of using this material as one of the components in ternary cement replacement.

\section{Methodology}

\section{Materials and Mix proportions}

Industrial wastes used as cement replacement in Industrial Waste Modified Mortar (IWMM) were Micro Silica from Grace Construction Sdn. Bhd. and Waste Vase from Local Cement used in this research is Ordinary Portland Cement (OPC) (ASTM Type 1 recognized by ASTM C150) manufactured by Cahaya Mata Sarawak Cement Sdn. Bhd (CMS). The chemical and mineralogical characteristics of the OPC, MS and FGWV $(<75 \mu \mathrm{m})$ are given in Table 1.The mix proportion for all samples are tabulated in Table 2. Modified porosity and compressive strength tests according to 